\title{
Validating a Phenomenological Mathematical Model for Public Health and Safety Interventions Influencing the Evolutionary Stages of Recent Outbreak for Long-Term and Short-Term Domains in Pakistan
}

\author{
Ahsan Nawaz $\mathbb{D}^{1},{ }^{1}$ Xing Su $\mathbb{D}^{1},{ }^{1}$ Shahid Iqbal, ${ }^{2}$ Hafiz Zahoor $\mathbb{D}^{3},{ }^{3}$ Ali Asad, ${ }^{4}$ Sana Asghar, \\ Farwa Basit, ${ }^{6}$ Muhammad Qasim Barkat, ${ }^{7}$ Amir Souhail, ${ }^{8}$ and Syyed Adnan Raheel Shah ${ }^{9}$ \\ ${ }^{1}$ Institute of Construction Project Management, CCEA, Zhejiang University, Hangzhou 310058, China \\ ${ }^{2}$ Management Studies Department, Bahria University, Islamabad, Pakistan \\ ${ }^{3}$ Construction Engineering \& Management Department, National University of Sciences and Technology, Risalpur Campus, \\ Risalpur, Pakistan \\ ${ }^{4}$ School of Management, Shenzhen University, Shenzhen, Guangdong 518060, China \\ ${ }^{5}$ School of Life Sciences, Zhejiang University, Hangzhou 310058, China \\ ${ }^{6}$ School of Agriculture \& Biotechnology, Zhejiang University, Hangzhou 310058, China \\ ${ }^{7}$ Department of Pharmacology, School of Medicine, Zhejiang University, Hangzhou 310058, China \\ ${ }^{8}$ The Bio Robotics Institute, Scuola Superiore Sant'Anna, Viale Rinaldo Piaggio 34, Pontedera, 56025, Pisa, Italy \\ ${ }^{9}$ Department of Civil Engineering, Pakistan Institute of Engineering \& Technology, Multan, Pakistan
}

Correspondence should be addressed to Ahsan Nawaz; ahsanklasra@zju.edu.cn and Xing Su; xsu@zju.edu.cn

Received 27 August 2020; Revised 13 September 2020; Accepted 16 September 2020; Published 1 October 2020

Academic Editor: Mostafa M. A. Khater

Copyright (C) 2020 Ahsan Nawaz et al. This is an open access article distributed under the Creative Commons Attribution License, which permits unrestricted use, distribution, and reproduction in any medium, provided the original work is properly cited.

During the outbreak of an epidemic, it becomes significantly essential to monitor the effects of containment measures and forecast the outbreak, including the epidemic peak. Many countries have either implemented strict lockdown to counter the spread of coronavirus disease or taken necessary preventive measures across the world to reduce the outbreak of this epidemic war. Several epidemic models have been presented across the world to examine the effects of public health-related strategies on mitigating the spread of current infectious disease, yet no reputable model has been presented for Pakistan as well as other South-Asian developing countries as per the authors' knowledge. In this research, an actual coronavirus prediction in Pakistan is presented, which may guide the decision-makers as to how this pandemic has spread across the country and how it can be controlled. Furthermore, in the absence of targeted medicines, the analysis helps to develop a precise plan for the eradication of the outbreak by adopting the calculated steps at the right time. The mathematical phenomenological models have been adopted in this study to predict, project, and simulate the overall affected cases reflected due to the recent outbreak in Pakistan. These models predict the expected growth, and the estimated results are almost well matched with the real cases. Through the calibration of parameters and analyzing the current situation, forecast for the appearance of new cases in Pakistan is reported till the end of this year. The constant level of number of patients and time to reach specific levels are also reported through the simulations. The drastic conditions are also discussed which may occur if all the preventive restraints are removed. This research quantitatively describes the significant characteristics of the spread of corona cases. It acknowledges and provides an understanding of a short-term and long-term transmission of coronavirus outbreak in the country as three evolutionary phases. Therefore, this research provides a pathway to cope with the emerging threat of a severe outbreak in developing and nondeveloping countries. 


\section{Introduction}

The number of identified cases increased gradually in the province of Hubei, Wuhan city, China, since the novel 2019 coronavirus was discovered in late December 2019. The Chinese government has implemented major spread prevention measures, such as the quarantine of the city of Wuhan and shutting off roads for all Hubei cities by the end of January 2020. Amid this measure, the outbreak spread globally and the World Health Organization has declared it an epidemic $[1,2]$. Consequently, a rapid rise in outbreak cases became a global emergency and a major health issue. Nowadays, the epidemic spread is a collective global public health concern, which constitutes serious political, economic, and social challenges. Efforts are being made to restrict and minimize the spread of this virus worldwide. The characteristics of corona are high infectivity, persistent incubation period, identification challenge, and complexity in how the disease is spreading. Unity is, therefore, recognized and considered as an essential necessity to fight against coronavirus during this period.

Various research studies have been conducted on the epidemiological study of modeling and forecasting [3] to tackle the spread of epidemic disease in order to provide not only the analytical predictions according to their size but also the ending phase of spread. Kuniya [4] has predicted the peak of the current epidemic disease through the application of the compartmental model "Susceptible-Exposed-Infected-Recovered (SEIR)" to provide the feasible insight for the Summer Olympics of 2020 to be held in Japan. Al-qaness et al. [5] applied Flower Pollination Algorithm (FPA) modified model together with the Salp Swarm Algorithm (SSA) in order to estimate the exact cases of corona in China for ten days. Koczkodaj et al. [6] predicted that the cases of corona outside China will rise by 1 million by a specific date on the basis of WHO heuristic situation reports. Wu et al. [7] have measured the outbreak of Wuhan and calculated the magnitude of the epidemic's international and domestic threats to public health based on the social and antidrug spreading interventions. Younes [8] used the Lotka-Volterra model coupled with Kalman Filter Algorithm model. It was predicted that the epidemic could be controlled in a few weeks by adhering to social distancing and banning all types of traveling; otherwise, more cases will rise in upcoming days. Wang et al. [9] applied the Generalized Logistic Growth Model (GLGM), Richards Growth Models (RGM), and Subepidemic Wave Model. They conducted a modeling study in Zhejiang and Guangdong provinces of China and predicted that the ratio of cases is slowing down in both provinces.

Pinter et al. [10] used Susceptible-Infected-Resistant (SIR) model, Adoptive Network-Based Fuzzy Interference System (ANFIS), and Multi-Layered Perception-Imperialist Competitive Algorithm (MLP-ICA) model to conclude that fewer number of cases were reported in Hungary and projected that overall cases and mortality rate will significantly decrease in Hungary at the end of May 2020. Reno et al. [11] applied SEIR model and concluded that, in Italy, preventive measures would strictly be imposed for a long term in Lombardy due to an increase in the number of hospitalized patients but in Emilia Romagna fewer cases were reported than Lombardy, Italy. Sanchez-Caballero et al. [12] applied the Verhulst equation-based model and concluded that China had started complete lockdown when the number of cases was 571 while Italy and France imposed partial lockdown when 12462 and 5678 cases were reported, respectively. In addition, the increased number of cases in Italy or France compared to China is just due to not adhering to the early preventive measures and delaying in lockdown. To date, scientists, engineers, and social scientists have been making rapid use of analytical data that are beneficial for decision-making in public and health organizations and to predict local and global challenges. Some of the previous research studies investigated epidemic spread, based on the projection and predicting models, as mentioned in Table 1. Different nations have made different preventive measures to respond to various outbreak patterns. Such interventions measures and their effect on spread should be reported if an effective containment strategy is to be enforced. Worldwide, epidemic has a negative impact on the education system, public life, economy, and the social life.

The WHO [16] officially declared Global Health Emergency for outbreak on January 30, 2020. Within two months of that declaration, the first major pandemic over a century has been driven by coronavirus [2]. The number of valid cases of COVID-19 and mortality continues to grow rapidly, with serious impacts on local and global economies without a definite end in sight. The governments of many countries have adopted lockdowns and other measures to limit the transmission of epidemics in several respects. Over the past few months, several models have been developed at the national and provincial levels to examine the possible effects of coronavirus transmission mitigation strategies. Pakistan is an independent state having a population of 220 million [17]. The first case of epidemic was reported on 26 February [1]. Most of the cases were transported from foreign travelers and not triggered by local transmission. Pakistan has therefore made intensive efforts to eradicate and quarantine the pandemic outbreak, maintain an efficient and robust health system, and reduce the time needed to reach an epitome of epidemic. The containment measures presented in Table 2 were taken from Pakistan's official releases $[1,18]$.

The intervention measures are aimed at reducing the contact between people, thus limiting the outbreak. These interventions include decreasing the disease rate among the elderly and those with chronic health conditions, mitigating the risk of spread among care and medical workers, significantly reducing mortality rate, and maintaining the health-care system. The Pakistani government shall take suitable action as nonmedicinal initiatives to minimize the outbreak impact [2]. In addition, Polymerase Chain Reaction (PCR) tests by the Pakistan Health Ministry were conducted to diagnose all international visitors for transmission [32]. As a result of the containment measures, the number of diagnosed infected cases of corona gradually increased. Citizens coming back from Iran and the Kingdom of Saudi Arabia were mostly 
TABle 1: Previous studies model and targeted predictions.

\begin{tabular}{|c|c|c|}
\hline Sr. No. & Model & Measures/predictions \\
\hline 1 & $\begin{array}{l}\text { Susceptible-Exposed-Infected-Recovered (SEIR) compartment } \\
\text { model }\end{array}$ & $\begin{array}{c}\text { Possible peak might be reached in early summer and } \mathrm{n} \\
\text { ended quickly in Japan [4] }\end{array}$ \\
\hline 2 & $\begin{array}{c}\text { Flower Pollination Algorithm Salp Swarm Algorithm-Adoptive } \\
\text { Neuro-Fuzzy Interference System (FPASSA-ANFIS) }\end{array}$ & Predicting the number of corona cases in upcoming 10 days [5] \\
\hline 3 & $\begin{array}{c}\text { Susceptible-Exposed-Infected-Recovered metapopulation } \\
\text { model }\end{array}$ & $\begin{array}{l}\text { It was forecasting the extent of domesti } \\
\text { health risks of the epidemi }\end{array}$ \\
\hline 4 & Heuristic and WHO- & It was forecasting the nu \\
\hline 5 & Lotka-Volterra model coupled with Kaman Filter Algorithm & $\begin{array}{l}\text { Epidemic could be controlled with restriction of traveling and } \\
\text { social distancing [8] }\end{array}$ \\
\hline 6 & $\begin{array}{c}\text { Generalized Logistic or Richards Growth Models and } \\
\text { Subepidemic Wave Model }\end{array}$ & $\begin{array}{l}\text { It was concluded that } \mathrm{t} \\
\text { Guar }\end{array}$ \\
\hline 7 & $\begin{array}{l}\text { Susceptible-Infected-Resistant (SIR) model, Adaptive Network- } \\
\text { Based Fuzzy Interference System (ANFIS), and Multi-Layered } \\
\text { Perception-Imperialist Competitive Algorithm (MLP-ICA) }\end{array}$ & $\begin{array}{l}\text { In Hungary, the death rate and overall corona cases dropped } \\
{[10]}\end{array}$ \\
\hline 8 & $\begin{array}{l}\text { Susceptible-Exposed-Infected-Recovered (SEIR) compartment } \\
\text { model [11] }\end{array}$ & $\begin{array}{c}\text { A decreased number of cases in Emilia Romagna compared to } \\
\text { Lombardy in Italy were predicted [10] }\end{array}$ \\
\hline 9 & Verhulst equation-based model & $\begin{array}{l}\text { It was concluded that China had reported a fewer number of } \\
\text { cases than Italy and Spain due to adhering to the precautionary } \\
\text { measures and imposing complete lockdown }[14]\end{array}$ \\
\hline 10 & $\begin{array}{l}\text { Motivation, Context, Interactivity, Evaluation, and Connectivity } \\
\text { (MCIEC) model }\end{array}$ & It was predicted \\
\hline
\end{tabular}

Table 2: Containment measures taken by the Pakistan Federal Government for COVID-19 (updated till May 30, 2020).

\begin{tabular}{|c|c|}
\hline Dates & Measures \\
\hline 12 February & $\begin{array}{c}\text { National Action Plan (NAP) was presented by the Ministry of Health Pakistan in order to tackle the current COVID-19 } \\
\text { outbreak across the country [19] }\end{array}$ \\
\hline 23 February & $\begin{array}{l}\text { Pakistan closed the Taftan border and banned all traveling concerns from Iran due to an increase in the number of cases } \\
\text { reported in Iran [20] }\end{array}$ \\
\hline 26 February & The first 2 corona cases were reported in Pakistan. Both cases recently came back from Iran [20] \\
\hline 29 February & Two more corona cases were reported in Rawalpindi and Islamabad, making a total of 4 cases reported till date [21] \\
\hline 2 March & \\
\hline 4 March & $\begin{array}{r}\text { Pakistan Civil Aviation Authority (CAA) started preventive measures such as sc } \\
\text { Peshawar airports, as many cases were reported in the neighbor }\end{array}$ \\
\hline 6 March & The first coronavirus patient ws \\
\hline & \\
\hline 9 March & $\begin{array}{l}\text { Pakistan extended the closure of the border with Afghanistan for one more week due to an increase in reported corona cases } \\
\text { in Karachi [24] }\end{array}$ \\
\hline 11 March & More number of COVID-19 suspected cases were reported in \\
\hline 13 March & $\begin{array}{l}\text { Educational institutes were closed till } 5 \text { April. All bor } \\
\text { well as suspending all international flights at Islamal }\end{array}$ \\
\hline & Pakistan Cricke \\
\hline & \\
\hline & \\
\hline 23 March & $\begin{array}{r}\text { Lockdown across Pakistan was announced and all types of movement a } \\
\text { out to buy food or medic }\end{array}$ \\
\hline 27 March & $\begin{array}{l}\text { A guard of honor was presented to all medical staff by military or police force for providing health-care services during } \\
\text { COVID-19 outbreak [20] }\end{array}$ \\
\hline 31 March & $\begin{array}{l}\text { A } 100 \text { billion rupees relief package was approved to fulfill the needs of } 12 \text { million needy people. Each needy family will get } \\
12000 \text { rupees for } 4 \text { months as a mark of assistance [31] }\end{array}$ \\
\hline & A total of 2708 cases were reported along with $5 \mathrm{de}$ \\
\hline 6 April & $\begin{array}{c}\text { Dr. Sania (Health Ministry release) said that a } 30.5 \text { million grant was received by the Government of Pakistan as public relief } \\
\text { package [33] }\end{array}$ \\
\hline 9 April & manufacturing hand sanitizers according to the WHO guidelines [1] \\
\hline $13 \mathrm{~A}$ & $\begin{array}{l}\text { A } 120 \text {-bed quarantine center } \\
\text { and } 26 \% \text {, respectively. Likewis }\end{array}$ \\
\hline & WHO provided 15 Polymerase Chain Reaction (PCR) machines and 15000 testing kits for assistance against COVID-19 [1] \\
\hline
\end{tabular}


TABLE 2: Continued.

\begin{tabular}{|c|c|}
\hline Dates & Measures \\
\hline 16 April & $58 \%$ corona infected cases were locally transmitted in Pakistan [30] \\
\hline 21 April & $27 \%$ of cases were transmitted by religious mass gathering $[25]$ \\
\hline 24 April & The lockdown was further extended till 9 May due to an uncontrolled number of cases [34] \\
\hline 7 May & $\begin{array}{c}500 \text { health-care workers got infected across the country. Mostly female health staff attending the patients in maternity wards } \\
\text { were infected [32] }\end{array}$ \\
\hline 9 May & Lockdown ended in Pakistan $[20,32]$ \\
\hline 21 May & Total cases crossed 48000 with 1017 deaths and 14155 recovered cases. Pakistan could test up to 25000 cases per day [35] \\
\hline 29 May & About 900 children under 10 years of age have been infected in Sindh but mostly were asymptomatic [36] \\
\hline 30 May & A total of 69496 cases were reported in Pakistan. They include 42742 active cases, 1483 deaths, and 25271 recovered cases [32] \\
\hline
\end{tabular}

Note: the data has been analyzed from 12 February to 30 May (109-day survey).

infected and later on, they became the cause of the spread of the transmission $[18,19]$. Nevertheless, some of the cases that have been reported recently are locally transmitted. This resulted in a dramatic rise in the early days in the number of cases.

The Government of Pakistan introduced many protective actions to safeguard the community, including sanitary education, patient isolation, and quarantine facilities, closing of key entrance points on state borders, closure of educational institutions, business centers, and the start of clinical testing and epidemiological monitoring. Around each other, such efforts require measured steps for optimal allocation of precautionary measures, structure of manufacturing processes, health supplies, and gradual stabilization of economic growth across the region. In the present contribution, an analytical approach is developed based on phenomenological models (DEGM, DG ${ }^{2} \mathrm{M}, \mathrm{DGLM}$, and DGRM). The research effort has allowed an important forecast to control the country's rapidly increasing pandemic in both short- and longterm zones. In addition, the possible impact on pandemic spread in Pakistan is analyzed, keeping in mind existing preventive measures. This research may classify the original contributions as (1) to present the mathematical phenomenology approach to simulate the outbreak spread in Pakistan, in order to estimate the scale of the epidemic, reproductive number, and final phase of the outbreak, (2) to project the evolutionary stages and provide an understanding of controlling its spread in the short-time and long-term domains, (3) to assess the current government's quick response and their effectiveness in containing outbreak spread in Pakistan with various preventive measures, and (4) to provide a prediction of outbreak distribution amid the repatriation plan for the political authorities of Pakistan for effective intervention.

\section{Materials and Methods}

2.1. Phenomenological Mathematical Models. The phenomenological models (Exponential Growth Model [37], Generalized Growth Model [38], Generalized Logistic Growth Model [39], and Generalized Richards Growth Model) [40] are articulated by the following differential equations, respectively [41-43]:

$$
\begin{aligned}
\frac{\mathrm{d} C(t)}{\mathrm{d} t} & =r C(t), \\
\frac{\mathrm{d} C(t)}{\mathrm{d} t} & =r C(t)^{p}, \\
\frac{\mathrm{d} C(t)}{\mathrm{d} t} & =r C(t)^{p}\left[1-\left(\frac{C(t)}{K}\right)\right], \\
\frac{\mathrm{d} C(t)}{\mathrm{d} t} & =r C(t)^{p}\left[1-\left(\frac{C(t)}{K}\right)^{\alpha}\right] .
\end{aligned}
$$

The mathematical models were thoroughly taken into account to describe past epidemics. The total estimated cases at time $t$ are shown by $C(t)$. Equation (4) then enhances the initial Richard Model of Growth [44] that explains the outbreak [45-49]. In this case, $r$ is the early growth rate; the overall size of the outbreak (spread) is described by $K$; the term $p$ describes the parameters which helps to extract the epidemic growth of the model; and the exponent's measures are labeled by $\alpha$ which shows the variation from the single logistic curve structure. Equation (4) is the same as the original form of Richard formula $(p=1)$; that is,

$$
\frac{\mathrm{d} C(t)}{\mathrm{d} t}=r C(t)\left[1-\left(\frac{C(t)}{K}\right)^{\alpha}\right] .
$$

In GL model, the value of $\alpha$ and $p$ is restricted to 1 . Although data was built in terms of confirmed cases, modifications, and fatalities, the variations in term $C$ can be taken into account over a unit time interval. The rate of change is expressed in $C$, that is, in $C(t)$, differently as $\Delta C / \Delta t$. The changes in positive patients are $\Delta C=C_{n+1}-C_{n}$. So, in a discrete form, equation (4) is remodeled as

$$
C_{n+1}=C_{n}+r C_{n}^{p}\left[1-\left(\frac{C_{n}}{K}\right)^{\alpha}\right],
$$

where the overall cases are reflected by $C_{n}$ on the $n$th day. The DGRMs, which are designed for mapping the pandemic, link the accumulative data on day $n$th with $(n+1)$ th day. The stable points in equation (6) for a DGRM are $C_{n}=0$, which means no patient was tested positive, and $C_{n}=K$, which means the number of patients reaches the final size. The 
stable levels are similar to those reached by the GRM. Further, we write the $\mathrm{DG}^{2} \mathrm{M}[50]$ as

$$
C_{n+1}=C_{n}+r C_{n}^{p} \text {. }
$$

It brings an exponential increase for the value of $p$, which is equal to 1 , which is $C_{n+1}=C_{1}(1+r)^{n}$, linear growth for the parameter $p=0$ relative to $n$ as $C_{n+1}=C_{1}$ $+n r C_{n+1}=C_{1}+n r$, and $(0<p<1)$ for the subexponential growth.

\section{Analysis and Results}

In the absence of medicines to control and monitor the outbreak, strict measures need to be adopted at the right time; therefore, besides the data evaluation, a clear public awareness, life, and economic risk management are essentially required. In all the provinces of Pakistan, regular pandemic growth identifies an overall increase in reported corona recovered and active cases, including mortality rate (death) which is reflected through blue color (dots) in Figure 1, which is tested using $\mathrm{DG}^{2} \mathrm{M}$, Discrete Logistics Growth Models (DGM), and DGRM mathematically. Such models have been used in the United States, Arab, Asian, and European countries to comprehend the epidemic [37-39, 41-43, 51].

\subsection{Epidemic Spread and Evolutionary Phases in Pakistan}

3.1.1. Phase 1: 26 February to 15 March. On 26 February 2020 in Pakistan, the first two confirmed cases have been registered. The pandemic expands significantly throughout the country due to having a lack of the governance and public awareness and absence in the complete lockdown strategy. Comparing the data (real time) with numerical model results confirms the exponential growth of the outbreak at an absolute rate of 0.85 . Figures 1 and 2 reflect the $\mathrm{DG}^{2} \mathrm{M}$ results in the red-dashed line.

Figure 1 illustrates the growth of reported coronavirus patients $\left(C_{n}\right)$ in the country measured against the period of time (number of days, $n$ ). In the graph, blue dots reflect the real-time data. The $\mathrm{DG}^{2} \mathrm{M}$ curve for the value of $p=0.875$ (reflecting the red-dashed line) and $r=0.3$ shows the total number of confirmed cases of COVID-19 in the first twenty days. In the first twenty days, overall reported cases follow $\mathrm{DG}^{2} \mathrm{M}$ curve for $r=0: 3$ and $p=0.875$ (red-dashed line). The $\mathrm{DG}^{2} \mathrm{M}$ curve for the value of $p=0.74$ (shown in blue color) and $r=0.74$ represents the real-time data in phase 3 .

3.1.2. Phase 2: 16 March to 31 March. In the next 15 days as shown in Figure 2, the entry for zairin from Iran, Tablighi Jamaat members, and the country citizens incoming through overseas on special flights induced the sudden rise in the number of confirmed cases. Lack of testing and quarantine facilities, returning of zairin to their home cities, and unexpected strain of people with previous international traveling background put significant pressure on economic resource limitations and health-care setup. Poor governance has led the country to combat the increasing epidemic cases a long way forward.

3.1.3. Phase 3: 03 April to 08 May. The governance tries to combat the outbreak across the country in the next 38 days of quarantining by combatting public movement, implementing social distancing, surveillance and controlling, shutting down educational institutions, playgrounds, and hotels, and restricting air and road travels. The exponential growth has been declined from 0.85 (value of phase 1) to the value of a new exponent 0.74 which represents the $D G^{2} M$ curve in blue line in Figure 2.

The confirmed cases in Pakistan have been represented by the $\log$ plot in Figure 2, in which $\log \left(C_{n}\right)$ along with days $n$ is plotted on 26 February 2020. The blue dots reflect the real-time data. In the first twenty days, the number of confirmed cases is followed by $\mathrm{DG}^{2} \mathrm{M}$ curve with $p=0.875$ which is drawn in red-dashed line in the graph and the value of $r=0.3$. The $\mathrm{DG}^{2} \mathrm{M}$ curve meets/followed the real-time data for $p=0.74$ denoted by blue line and (1st value) and $r=0.74$ to the value of a new exponent 0.74 which represents the $\mathrm{DG}^{2} \mathrm{M}$ results in blue line in Figure 2.

The measures taken in phase 3 to remove the pandemic effect in the country resulted in the identification of 28736 cases, including 20291 active cases, 636 deaths, and 7809 cases rescued. The statistical analysis shows a red- and bluedashed lines that correlate in real time to the second week of May. It reflects that, at stage 1 , the number of reported epidemic cases today was the same without any lockdown and public awareness drive. In phase 2, the country allowed foreigners to have a previous traveling background to enter only after proper screening and passing through the quarantine period. These lockdown measures have damaged the country's economy at stages 2 and 3. At the end of the day, they would have to pay the cost for entry of people with foreign history. It also revealed the poor situation in Pakistan in the early stages to cope with the pandemic.

3.1.4. Phase 4: 09 May to 15 May. The evaluation of coronavirus reported cases centered on DGRM and interpretation to 31 May indicates that the pandemic scale is expected to upsurge around sixty thousand cases over the next twenty-two days when the lockdown is implemented (as reflected in black-dashed narrow line in Figure 3). Furthermore, it indicates that we can significantly hold back the outbreak in the country up to August 2020 by accelerating lockdowns at this point. An enforced lockdown in this crucial stage will help to enable the country to handle the outbreak in the upcoming two months rather than relaxing lockdown. This limits the size of the epidemic to approximately 100,000 cases as shown in Figure 4. If the lockdown stops fully at phase 4 , the scale of the outbreak will increase to 120,000 coronavirus confirmed cases in the next twentytwo days as graphed by the red line in Figure 3. The number of COVID-19 confirmed cases is to be somehow between sixty thousand and one hundred twenty thousand if the lockdown is partially released. 


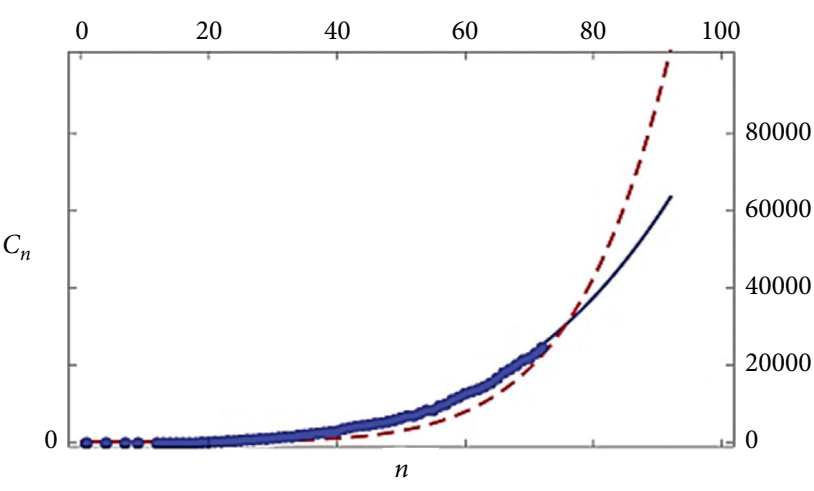

FIgURE 1: Epidemic confirmed $C_{n}$ cases with days $n$

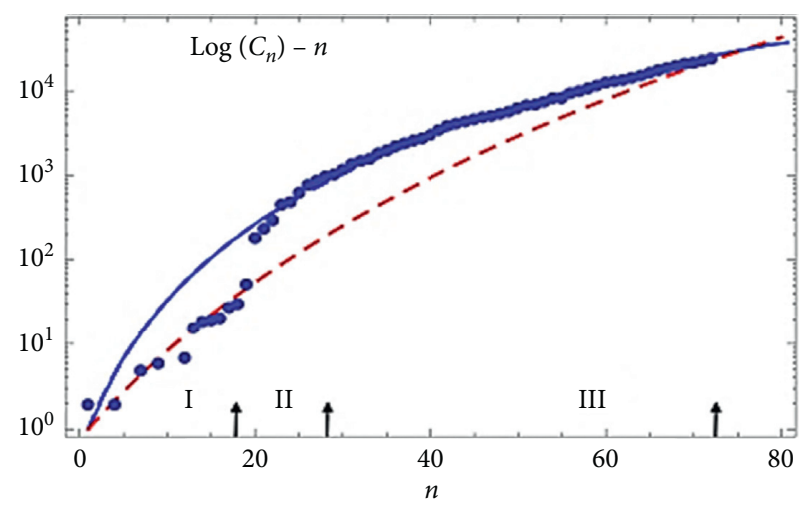

Figure 2: Confirmed epidemic $\log \left(C_{n}\right)$ cases with days $n$.

Figure 3 exemplifies the growth of COVID-19 confirmed patients $\left(C_{n}\right)$ followed by the $\mathrm{DG}^{2} \mathrm{M}$ curve (in black-dashed line) for $K=100000, \alpha=2, p=0.74$, and $r=0.74$ plotted against the number of days, $n$. The blue dots reflect the real time and the red line shows the $\mathrm{DG}^{2} \mathrm{M}$ results for $p=0.875$ and $r=0.3$.

3.1.5. Phase 5: 15 June to Continue. In an account of the holy Ramadan days and the required occupational needs of those days, the planned lockdown in phases 2 and 3 is relaxed in phase 4 . In the next month, a detailed and calculated approach is required for pandemic management. The country's pandemic size shall not increase by a lockdown scenario from May 09 to June 31. Through perceiving the DGRM results, a strict lockdown in June would carry around three hundred and fifty thousand confirmed cases in September, with a rise of less than one percent in the number of new cases per day as shown in Figure 4 (black curved line). At the end of August, the outbreak peak is expected to beat by about 200,000 reported cases. A compromised lockdown would allow epidemic cases at phase 4 to be managed by the end of August, with the projected epidemic scale about 250,000 cases as reflected in Figure 4 by the big black-dashed line.

Figure 4 describes the growth of confirmed patients $\left(C_{n}\right)$ followed by the $\mathrm{DG}^{2} \mathrm{M}$ curve (by red line) for $p=0.875$ and $r=0.3$ plotted against the number of days, $n$. The blue dots reflect the real-time data. The black-dashed line shows the results of DGRM curve for $K=100000, p=0.74, r=0.74$, and $\alpha=2$. Furthermore, the black-big-dashed line and the black line reflect the DGRM results for $K=250000$ and $K=350000$.

\section{Discussion}

Various scenarios were analyzed to provide policymakers with insights into the implementation of the appropriate intervention to mitigate the spread of the epidemic in Pakistan. The study used mathematical phenomenological models to estimate the daily and weekly peaks, total infected cases, and the estimated duration of the outbreak. In addition, the effects of preventive variation in the number of susceptible and infected populations were also investigated. Phenomenological models evaluated the effectiveness of methods of control such as social separation and lockdown. The Government of Pakistan has taken various control measures, as outlined in Table 2. In response to the outbreak, the measures are gradually increased to more restricted ones. The first measure was the NAP and the other measures include sealing the Taftan and Afghanistan borders, closure of school and universities all over the country, applying half and full lockdown, postponing the PSL, active participation of the Pakistan CAA in the closure of all international and national flights, manufacturing of hand sanitizers and face masks as per WHO guidelines, extension of lockdown, and relief package from the Government of Pakistan for the needy people. According to the Pakistan Bureau of Statistics, as of 1 January 2019, the proportion of people between 5 and 24 years of age accounts for approximately $25 \%$ of the total population [52]. Even though the early analysis indicating the low percentage of this age, the issue is very important because it can spread the disease to other age groups. In fact, a new WHO study disclosed a steady growth in the proportion of cases aged 20-39 [1]. The evolutionary phases describe the real scenario of cases: in the first phase, the first two patients have been diagnosed and due to having a lack in applying lockdown and people awareness operations, the pandemic had a blowout in the country in a very drastic way; in phase 2, the study projected that new cases emerged due to the arrival of citizens from foreign countries, thus, putting colossal pressure on the budgetary sources and health-care proper setup and making it difficult for the country to combat an increased number of coronaviruses cases; in phase 3 , the study predicted that exponential growth of cases had decreased from 0.085 (phase 1 value) to 0.074 (phase 3 value) due to the enforcement of quarantine strategy, combatting public movement, implementing social distancing, surveillance, shutting down educational institutions, and restricting train and road traveling. The elimination of the outbreak in Pakistan in phase 3 resulted in 28736 cases, including 20291 active, 7809 recovered, and 636 death cases. This indicates that, in phase 1 , the rate of total cases has been increased, leading to a lack of public awareness and applying lockdown. The cases increased in phase 2 as the country has allowed the entry of people having foreign travel history without any adequate checkup and 


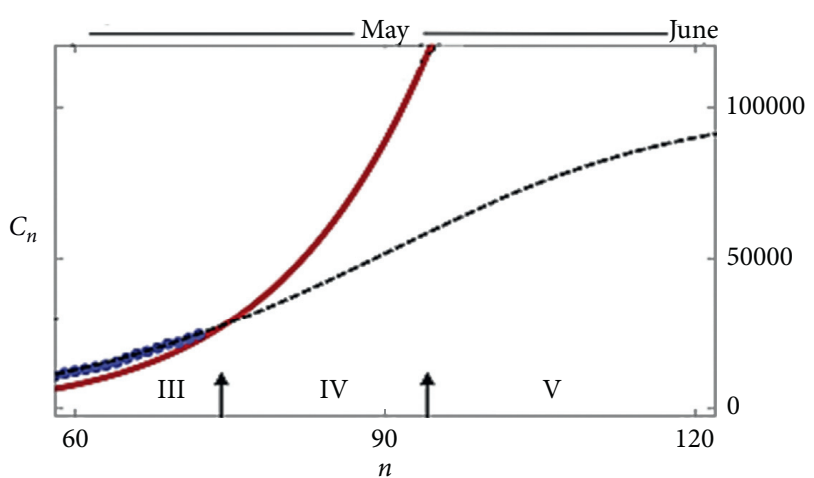

Figure 3: Confirmed epidemic $\left(C_{n}\right)$ cases with days $n$ up to the end of June.

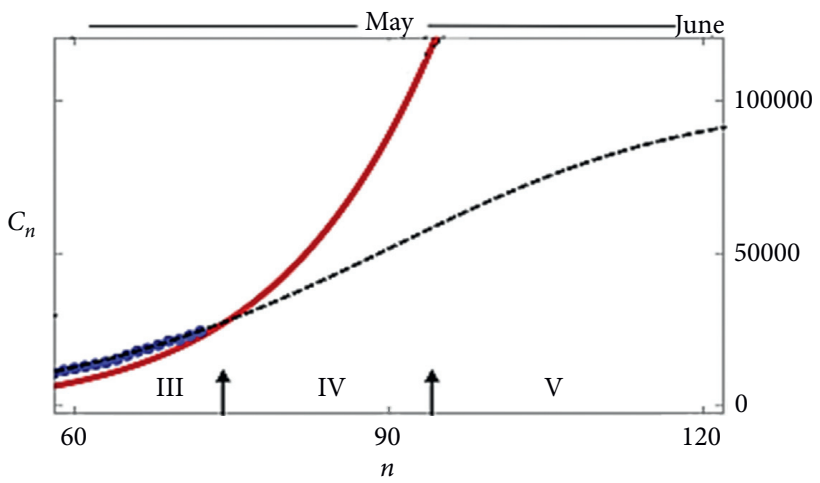

Figure 4: Confirmed COVID-19 $\left(C_{n}\right)$ cases with days $n$ up to the end of August.

quarantine. The study predicts that, even after enforcing complete lockdown in phase 3 , the number of corona cases would cross 60,000 at the end of May and it will further go on and reach 100,000 cases till the end of June. Either by lifting the lockdown or with smart lockdown, cases are likely to increase between 60,000 and 120,000 . So instead of relaxing the lockdown, a strict lockdown is obligatory to combat the outbreak effectively. The study projects that, even after enforcing strict lockdown in the month of June (in phase 4), the confirmed cases will rise to almost 350,000 at the end of August or the start of the month of September with 1\% increase in the newly identified cases per day. This number is likely to decrease after the end of December 2020. Although these estimates may vary with the passage of time, it will really help us to observe the most influential factors that cause an increase in the epidemic spread. On the basis of this analysis, competent authorities may design the most effective strategies in order to control the epidemic.

\section{Conclusion and Recommendations}

In this study, phenomenological mathematical models were used to assess the feasibility of the appearance of the recent outbreak in Pakistan as well as measuring the definitive number of patients according to the current situation. By comparing the model outcomes with confirmed cases, it has been established that the estimated values have realistic correspondence with the confirmed numbers. If the current pattern continues, Pakistan has to bear the burden of around 350,000 cases till the end of August or 1st week of September 2020 with an increase of $1 \%$ of newly identified cases per day. The situation may vary by the deviation in transmission rate, death rate, recovery rate, and further implementation of social distancing. The Government of Pakistan has relaxed the lockdown under some restrictions since 9 May, in order to support the business activity and reduce the economic crisis. Currently, the shopping malls, public markets, business centers, trains, and local transport are opening across the country. Since the opening of lockdown, the number of COVID-19 cases is likely to increase exponentially due to more chances of transmission among peoples. As a precautionary measure, the government has launched a public service campaign with the collaboration of media during the relaxation in lockdown periods, in order to provide preventive measures through video messages (1-2 minutes). Meanwhile, the emphasis is laid to strictly act upon prevention measures during the ongoing pandemic outbreak. The study recommends that health experts, motivational speakers, administrative authorities, media, and physiological experts should arrange online lectures and provide health education, to motivate the public to follow all the essential protective measures for their own and other people safety. The study recommends imposing a strict lockdown from June to July 2020 to control the contagious disease across the country. There is also a need to focus on the effective preparedness of the health sector and enhancing the technical expertise of all front line warriors. Besides, optimal allocation of preventive or precautionary measures, judicious utilization of available resources, and construction of all productive initiatives would get the country away from the global pandemic. On the other hand, mismanagement and delayed responses are expected to increase the spread of the pandemic and result in excessive economic loss in the coming months.

\section{Data Availability}

The data used to support the findings of this study are available from the corresponding author upon request.

\section{Conflicts of Interest}

The authors declare no conflicts of interest.

\section{Acknowledgments}

This research was fully funded by the China Scholarship Council and National Natural Science Foundation of China (71971196).

\section{References}

[1] WHO, Corona Virus Disease (COVID-19) Pandemic, WHO, Geneva, Switzerland, 2020, https://www.who.int/emergencies/ diseases/novel-coronavirus-2019.

[2] A. M. Almeshal, A. I. Almazrouee, M. R. Alenizi, and S. N. Alhajeri, "Forecasting the spread of COVID-19 in Kuwait using compartmental and logistic regression models," Applied Sciences, vol. 10, no. 10, p. 3402, 2020. 
[3] S. Boccaletti, W. Ditto, G. Mindlin, and A. Atangana, "Modeling and forecasting of epidemic spreading: the case of Covid-19 and beyond," Chaos, Solitons, Fractals, vol. 135, 2020.

[4] T. Kuniya, "Prediction of the epidemic peak of coronavirus disease in Japan, 2020," Journal of Clinical Medicine, vol. 9, no. 3, p. 789, 2020.

[5] M. A. A. Al-qaness, A. A. Ewees, H. Fan, and M. Abd El Aziz, "Optimization method for forecasting confirmed cases of COVID-19 in China," Journal of Clinical Medicine, vol. 9, no. 3, p. 674, 2020.

[6] W. W. Koczkodaj, M. A. Mansournia, W. Pedrycz et al., "1,000,000 cases of COVID-19 outside of China: the date predicted by a simple heuristic," Global Epidemiology, vol. 2, Article ID 100023, 2020.

[7] J. T. Wu, K. Leung, and G. M. Leung, "Nowcasting and forecasting the potential domestic and international spread of the 2019-nCoV outbreak originating in Wuhan, China: a modelling study," The Lancet, vol. 395, no. 10225, pp. 689-697, 2020.

[8] A. B. Younes, "Applied sciences COVID-19," Modeling, Prediction and Control, vol. 10, no. 11, pp. 1-14, 2020.

[9] C. Wang, Z. Cheng, X.-G. Yue et al., "Risk management of COVID-19 by universities in China short-term forecasts of the COVID-19 epidemic in Guangdong and Zhejiang, China: February 13-23, 2020," Journal of Risk and Financial Management, vol. 13, pp. 1-9, 2020.

[10] G. Pinter, I. Felde, A. Mosavi, P. Ghamisi, and R. Gloaguen, "COVID-19 pandemic prediction for Hungary; A hybrid machine learning approach," SSRN Electronic Journal, vol. 8, 2020.

[11] C. Reno, J. Lenzi, A. Navarra et al., "Forecasting COVID-19associated hospitalizations under different levels of social distancing in Lombardy and Emilia-Romagna, Northern Italy: results from an extended SEIR compartmental model," Journal of Clinical Medicine, vol. 9, no. 5, p. 1492, 2020.

[12] S. Sanchez-Caballero and M. A. Selles, "An efficient COVID19 prediction model validated with the cases of China, Italy, and Spain: total or partial lockdowns?" SSRN Electronic Journal, vol. 9, no. 5, 2020.

[13] R. Lu, X. Zhao, J. Li et al., "Genomic characterisation and epidemiology of 2019 novel coronavirus: implications for virus origins and receptor binding," The Lancet, vol. 395, no. 10224, pp. 565-574, 2020.

[14] S. M. Jenness, S. M. Goodreau, and M. Morris, "EpiModel: an $\mathrm{R}$ package for mathematical modeling of infectious disease over networks," The Journal of Statistical Software, vol. 84, 2018.

[15] A. Moreno-Guerrero, I. Aznar-Díaz, and C. Pilar, "E-learning in the teaching of mathematics : an educational experience in adult high school," 2020.

[16] WHO, WHO Coronavirus Disease (COVID-19), WHO, Geneva, Switzerland, 2020, https://covid19.who.int.

[17] PBOS Paksitan Bureau of Statistics, 2020, http://www.pbs.gov. $\mathrm{pk} /$ content/population-census.

[18] MNHS The Minitry of National Health Services, http://www. nhsrc.gov.pk/.

[19] Ministry of National Health Services, National Action Plan for Preparedness \& Response to Corona Virus Disease (COVID19), Ministry of National Health Services, Islamabad, Pakistan, 2020, http://htpps//www.nih.org.pk.

[20] "Dunia newspaper Pakistan response," 2020, https://e.dunya. com.pk/splash.php.
[21] Pakistan today two coronavirus cases confirmed in Pakistan, http://www.pakistantoday.compk, 2020.

[22] The Guardian Turkey and Pakistan close borders with Iran over coronavirus deaths, Coronavirus outbreak, http://amp. theguardian.com, 2020.

[23] NIHP Pakistan on high alert amid coronavirus outbreak in China, 2020, http://www.samaa.tv.

[24] Geo News Coronavirus, "Pakistan extends border closure with Afghanistan for seven days," 2020, http://www.geo.tv.

[25] T. D. Newspaper, "Cov 19 rapid response," 2020.

[26] D. Time, "Schools, colleges and universities in Pakistan to remain closed till April 5 amid coronavirus outbreak," 2020.

[27] Gulf News Pakistan deploys army to assist in COVID-19 measures, 2020, http://gulfnews.com.

[28] Voice of America Pakistan Detects First Coronavirus Cases, Links to Iran Outbreak, 2020.

[29] Skif Europe Pakistan Shuts Borders Amid Coronavirus Outbreak, 2020, https://skift.com/2020/03/13/pakistan-shutsborders-amid-coronavirus-outbreak/.

[30] Gulf News Pakistan on high alert amid coronavirus outbreak in China, 2020, http://gulfnews.com.

[31] D. News, Multi-Billion rupees relief package approved, 2020.

[32] National Institute of Health, Islamabad, Pakistan, 2020, http:// www.nih.org.pk.

[33] National news PM announces record economic relief package, 2020.

[34] Gulf News Pakistan-extends-COVID-19-lockdown-untilMay-9, 2019.

[35] Aljazeera Pakistani Doctors decry lack of supplies as lockdown looms, 2020, http://www.aljazeera.com.

[36] Aljazeera Hundreds of children in Pakistan's Sindh infected with COVID-19, 2020, http://www.aljazeera.com.

[37] R. A. M. Attia, D. Lu, T. Ak, and M. M. A. Khater, "Optical wave solutions of the higher-order nonlinear Schrödinger equation with the non-Kerr nonlinear term via modified Khater method," Modern Physics Letters B, vol. 34, no. 5, 2020.

[38] M. M. A. Khater, J. F. Alzaidi, R. A. M. Attia, M. Inc, and D. Lu, "Analytical and numerical solutions for the current and voltage model on an electrical transmission line with time and distance," Physica Scripta, vol. 95, no. 5, p. 55206, 2020.

[39] J. Li, Y. Qiu, D. Lu, R. Attia, and M. Khater, "Study on the solitary wave solutions of the ionic currents on microtubules equation by using the modified Khater method," Thermal Science, vol. 23, no. Suppl 6, pp. 2053-2062, 2019.

[40] K. Wu, D. Darcet, Q. Wang, and D. Sornette, "Generalized logistic growth modeling of the COVID-19 outbreak in 29 provinces in China and in the rest of the world," 2020.

[41] C. Park, M. M. A. Khater, R. A. M. Attia, W. Alharbi, and S. S. Alodhaibi, "An explicit plethora of solution for the fractional nonlinear model of the low-pass electrical transmission lines via Atangana-Baleanu derivative operator," Alexandria Engineering Journal, vol. 59, 2020.

[42] M. M. A. Khater, D. Lu, and R. A. M. Attia, "Dispersive long wave of nonlinear fractional $\mathrm{Wu}$-Zhang system via a modified auxiliary equation method," AIP Advances, vol. 9, no. 4, Article ID 049902, 2019.

[43] L. Qian, R. A. M. Attia, Y. Qiu, D. Lu, and M. M. A. Khater, "The shock peakon wave solutions of the general DegasperisProcesi equation," International Journal of Modern Physics B, vol. 33, no. 29, Article ID 1950351, 2019.

[44] F. J. Richards, "A flexible growth function for empirical use," Journal of Experimental Botany, vol. 10, no. 2, pp. 290-301, 1959. 
[45] E. Shim, A. Tariq, W. Choi, Y. Lee, and G. Chowell, "Transmission potential and severity of COVID-19 in South Korea," The International Journal of Infectious Diseases, vol. 93, 2020.

[46] G. Chowell, L. Sattenspiel, S. Bansal, and C. Viboud, "Mathematical models to characterize early epidemic growth: a review," Physics of Life Reviews, vol. 18, pp. 66-97, 2016.

[47] G. Chowell, R. Luo, K. Sun, K. Roosa, A. Tariq, and C. Viboud, "Real-time forecasting of epidemic trajectories using computational dynamic ensembles," Epidemics, vol. 30, Article ID 100379, 2020.

[48] G. Chowell, "Fitting dynamic models to epidemic outbreaks with quantified uncertainty: a primer for parameter uncertainty, identifiability, and forecasts," Infectious Disease Modelling, vol. 2, no. 3, pp. 379-398, 2017.

[49] G. Chowell, D. Hincapie-Palacio, J. Ospina et al., "Using phenomenological models to characterize transmissibility and forecast patterns and final burden of Zika epidemics," PLoS Currents, vol. 8, 2016.

[50] F. Saif, "COVID-19 pandemic in Pakistan: stages and recommendations," 2020.

[51] D. Lu, A. R. Seadawy, and M. M. A. Khater, "Structures of exact and solitary optical solutions for the higher-order nonlinear Schrödinger equation and its applications in monomode optical fibers," Modern Physics Letters B, vol. 33, no. 23, p. 1950279, 2019.

[52] Pakistan Bureau of Statistics; Islamabad, Pakistan, 2017. 